\section{Дмитриев О.Н.}

д-р. экон. наук, канд. техн. наук, ФГБОУ ВО «Московский авиационный институт (национальный исследовательский университет)», г. Москва

e-mail: olegdmitriev@ya.ru

\section{Новиков С.В.}

канд. экон. наук, ФГБОУ ВО «Московский авиационный институт (национальный исследовательский университет)», г. Москва

e-mail: ncsrm@mail.ru

\section{Dmitriev O.N.}

Doctor of Economic Sciences, Candidate of Technical Sciences, Moscow aviation institute (national research university), Moscow

e-mail: olegdmitriev@ya.ru

\section{Novikov S.V.}

Candidate of Economic Sciences, Moscow aviation Institute (national research university), Moscow

e-mail: ncsrm@mail.ru

\section{Приоритетные концептуальные проблемы государственного регулирования операций в инновационной сфере в современных российских условиях}

\begin{abstract}
Аннотация
Аргументирована критичность инновационной активности применительно к сфере высокотехнологичного национального производства в сложившейся ситуации. Мотивированно констатировано существование системного инновационного кризиса в современной России. Выделен ряд причин его возникновения, существования и усугубления - как внутренних, так и внешних. Концептуально структурирована сфрера формирования и реализации инновационных операций применительно к сложившимся условиям функционирования российской экономики с преимущественной ориентацией на высокотехнологичное промышленное производство. Произведено разграничение сфер непосредственной реализации инновационных операций производителями новаций (новаторами) и их потребителями (инноваторами), а также обеспечительной сферы с выделением доноров возвратных заимствований - прежде всего банков, страховщиков, консалтинговых структур и структур поддержания внешней инфросфреры. Приведены структурно-функциональные аналогии с типовой сфрерой реализации маркетинговых операций. Привнесена типология инновационных операций по признаку стра`новой дислоцированности новаторов и инноваторов. Показано объективное доминирование инноваций по каналу импортирования новаций и внутрироссийскому каналу. Привнесена базовая типология регуляционных операций органов государственного управления применительно к инновационной и инвестиционной сфере. Акцентирована сфера организации конкурсов на выполнение заказов по производству новационных продуктов, комплексированная со соерой законодательного и иного нормативно-правового регулирования. Представлен анализ действующих базовых регламентов нормативно-правового регулирования в этой сфрере и производных, порождаемых проблем с учетом реалий материализации поведенческих моделей типизированных операторов инновационной ссреры. Предложен ряд принципиальных нововведений концептуального характера в области этого регулирования, в том числе в основном ориентированных на использование потенциала активности субъектов инновационной активности.
\end{abstract}

\section{Ключевые слова:}

инновационная среда, новация, инновация, инновирование, государственное регулирование, законодательство, нормативно-правовое регулирование, конкурсная организация инновирования.

\section{Priority conceptual problems of state regulation of operations in innovation sphere under modern russian conditions}

\begin{abstract}
The criticality of innovation activity in relation to the sphere of high-tech national production in the current situation is argued. The existence of a systemic innovation crisis in modern Russia is stated with motivation. A number of causes of its occurrence, existence and aggravation - both internal and external are singled out. The sphere of formation and implementation of innovative operations in relation to the current conditions of the Russian economy with a predominant focus on high-tech industrial production is conceptually structured. Produced the delimitation of spheres direct the implementation of innovative operations of producers of novations (novators) and their customers (innovators), as well as the service sphere, highlighting donors returnable borrowing - primarily of banks, insurance companies, consulting agencies and maintain the appearance of the infosphere. The structural and functional analogies with the typical sphere of marketing operations are given. The typology of innovative operations on the basis of country-based deployment of novators and innovators is introduced. Shows the dominance of the objective of innovation through the channel of import and domestic innovation channel. The basic typology of regulatory operations of public administration in relation to innovation and investment is introduced. The sphere of organization of tenders for the execution of orders for the production of innovative products, integrated with the sphere of legislative and other regulatory regulation, is emphasized. The analysis of the existing basic regulations of normative legal regulation in this sphere and the derivatives generated problems taking into account the realities of the materialization of behavioral models of the typed operators of the innovation sphere is presented. A number of fundamental conceptual innovations in the field of this regulation, including those focused on the use of the activity potential of the subjects of innovation activity, are proposed.
\end{abstract}

\section{Keywords:}

innovation environment, novation, innovation, innovating, state regulation, legislation, legal regulation, competition organization of innovating.

(C) The Author(s), 2018 This is an open access article under the CC BY 4.0 license (http://creativecommons. org/licenses/by/4.0/) 
K настоящему времени российская экономика находится в состоянии перманентного системного кризиса, в том числе - инновационного кризиса. Это обусловлено критичностью состояния и национальных инноваторов, и национальных новаторов, а также отечественных операторов, относящихся к области своего рода обеспечительной инновационной деятельности.

Удручающая парадигма состоит в том, что среди российских предприятий недопустимо мало тех, кто может выступить в роли критически важных новаторов (производителей, доноров новаций) и критически важных инноваторов (потребителей, реципиентов новаций). Это касается и внутрироссийского инновирования, и внероссийского инновирования.

Данная критичность связана во многом с катастрофической редуцированностью управленческого потенциала, по крайней мере, отечественных новаторов и инноваторов, формирующих управленческие решения по новациям и инновациям, а также с тем, что доступ отечественных предприятий на внешние рынки новационных продуктов ныне уже существенно ограничен или по некоторым позициям скорее даже закрыт [8]. Это произошло вследствие неразрешенных квалиметрических, маркетинговых и репутационных проблем, а также вследствие существования непосредственных и производно самоцензовых лимитированностей контрагентов, обусловленных реализованными и ожидаемыми к реализации антироссийскими санкциями. Несомненно, что мировой рынок новаций для российских предприятий пока еще в достаточной мере открыт в обоих направлениях. Однако, во-первых, решения по новационным и инновационным проектам принимаются недостаточно компетентно. Во-вторых, этот рынок имеет уже запрещенные для доступа и быстро расширяющиеся недоступные сегменты критически важных новаций. И в-третьих, российские и новаторы, и инноваторы являются в основной своей массе относящимися к типажным персонажам давно ушедшей инновационной эпохи.

Естественно, что обрисованная ситуация является принципиально неприемлемой и в части социального развития российского общества, и в части обеспечения его национальной безопасности.

\section{Результаты}

Структура среды инновирования топологически соответствует типовой маркетинговой среде (см. рис. 1) [9; 13]. В ней новаторы - суть первичные производители и первичные поставщики товарной продукции в виде новационных продуктов-новаций, а инноваторы - ее конечные потребители и конечные заказчики, преобразующие новации в прогрессорское приращение своего потенциала. При этом новационные продукты могут иметь характер товарной продукции как конструкционной компоненты, так и предметов, и орудий труда очередных по технологической цепочке субъектов производства.

Наряду с этими непосредственными участниками инновирования (обведены перфорационно подобной рамкой) выделяются и их обеспечительные субъекты (выделены между перфорационно подобной рамкой и штриховой рамкой).

Все выделенные субъекты объективно являются субъектами управления, но в рамках тематического рассмотрения ограничимся рассмотрением регулятивных воздействий только непосредственно со стороны органов государственного (федерального) управления. Эта позиция выделена двусторонней стрелкой с горизонтальной штриховкой.

С учетом стра́нового позиционирования можно выделить следующие подпадающие под рассмотрение виды инновирования с вовлечением российских лиц: внутрироссийское (новатор и инноватор - российские лица), экспортно-ориентированное (новатор - российское лицо, инноватор нероссийское лицо) и импортно-ориентированное (новатор - нероссийское лицо, инноватор - российское лицо).

Государственное регулирование инновационных операций может совершаться, прежде всего, посредством:

- трансформации законодательной и более широко - нормативно-правовой среды;

- участия в качестве субъекта инновационной деятельности в одном или нескольких статусах, рассмотренных выше (см. рис. 1) [10].

Рассмотрим более подробно, как ныне обстоят дела в области суперпозиции нормативно-правовых трансформаций и осуществлении конкурсно-контрактного регулирования инновационной деятельности российских предприятий.

При этом будем учитывать существенную специфику управления в новационно-инновационной сфере, усматривая в современной российской экономике корпоративные и псевдокорпоративные организационные обособления $[9 ; 10 ; 11 ; 12 ; 14 ; 15]$.

Общеизвестно, что в настоящее время расходование бюджетных средств в сфере научных проектов осуществляется двумя основными способами:

1) предоставление средств главным распорядителям бюджетных средств - федеральным органам исполнительной власти в нескольких формах; 


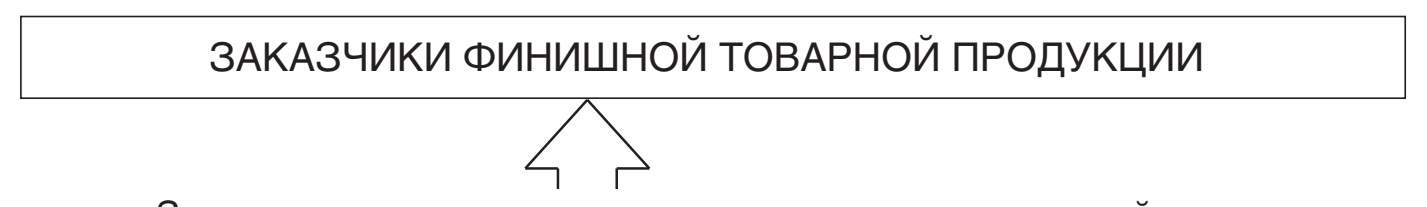

Заключение договоров поставки и исполнение их условий

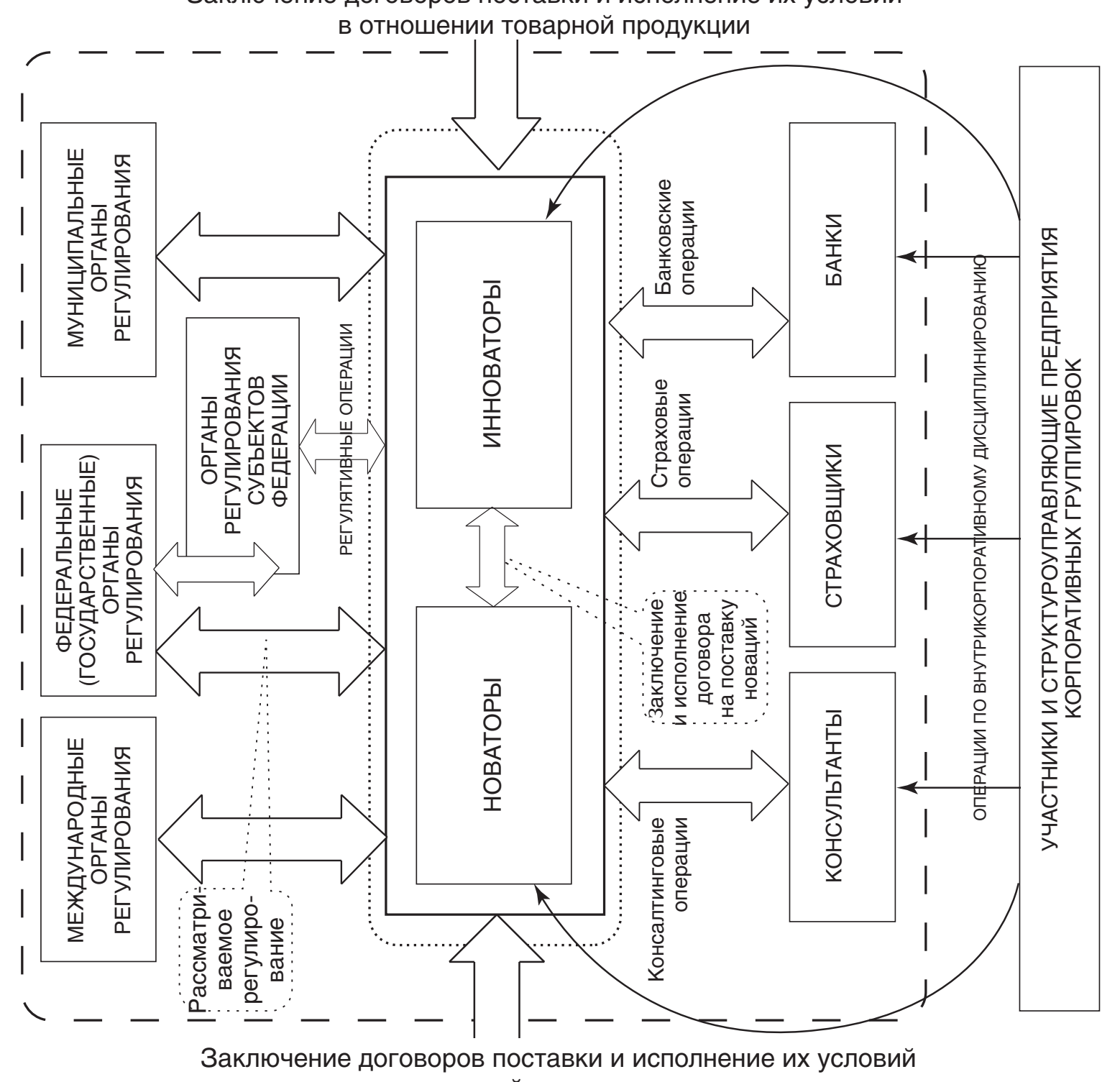

в отношении товарной продукции иных смежников

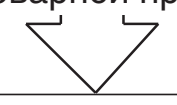

\section{ВНЕИННОВАЦИОННЫЕ ПРОИЗВОДСТВЕННЫЕ СМЕЖНИКИ}

Составлено авторами по материалам исследований

Рис. 1. Структура внутренней и внешней инновационной среды

2) предоставление средств государственным фондам поддержки научной, научно-технической и инновационной деятельности в форме субсидий на выдачу грантов.

Ряд способов относится к так называемому инициативному финансированию и предполагает формулирование тематик исследований самими заявителями, а также конкурсный отбор тематик. Данная система распределения средств соответствует лучшим зарубежным практикам стран, где эффективность научных исследований традиционно высока. 
Однако первые два вида финансирования в рамках первого способа, так называемое заказное финансирование, в настоящее время не содержат требований к порядку формирования тематик, что существенным образом влияет на эффективность исследований.

Проиллюстрируем решение указанной проблемы на примере государственного задания в сфере науки. При этом важную роль в регламентации института государственного задания играет Бюджетный кодекс Российской Федерации (далее - БК РФ) [1].

В настоящее время для всех федеральных государственных учреждений независимо от вида осуществляемой ими деятельности основными документами, регламентирующими порядок формирования государственного задания, является ряд подзаконных актов.

Отличительной особенностью соответствующих документов является наличие подробной информации, касающейся услуг, и самых общих формулировок относительно работ, результаты которых будут использоваться государством либо обществом в целом.

Отсутствие четких ориентиров для формирования государственного задания в сфере науки прослеживается уже на уровне базовых и ведомственных перечней государственных услуг (работ), утвержденных Министерство образования и науки России (далее - Минобрнауки) [4; 5 ; 6].

Однако ведомственный перечень государственных услуг не содержит никаких характеристик работ, выполняемых в сфере науки. При этом если единицы измерения показателя объема (содержания) вышеуказанных работ согласно ст. 69.2 БК РФ еще могут отсутствовать, то показатели, характеризующие качество работ, в любом случае должны быть определены в государственном задании (п. 1 ст. 69.2 БК РФ).

Соответственно в 2013-2017 гг. Минобрнауки России предприняло ряд мер, направленных на уточнение порядка формирования государственного задания в сфере науки организациями, подведомственными Минобрнауки России. В частности, было разработано и утверждено профильное положение [7].

В связи с тем, что во введенной им методике отсутствует порядок расчета размера субсидии (или хотя бы финансирования по одной из тем научноисследовательской работы) с учетом таких показателей, как результативность научной деятельности, результатов научных исследований, использование данного документа в практической деятельности федеральных органов исполнительной власти (далее - ФОИВ) при формировании государственного задания для подведомственных учреждений остается крайне ограниченным.

Ситуация должна была измениться введением постановления, в котором были внесены изменения, устанавливающие, что порядок определения нормативных затрат на оказание государственных услуг в сфере научно-исследовательской деятельности устанавливается главными распорядителями средств федерального бюджета с учетом методики определения нормативных затрат на оказание государственных услуг в сфере научно-исследовательской деятельности, утвержденной Минобрнауки России [3].

Следует отметить, что данные документы не могут решить одну важную проблему формирования государственных заданий - отсутствие контроля за дублированием тематик исследований на стадии формирования государственного задания, так как Минобрнауки России лишено возможности проконтролировать темы исследований при формировании государственного задания и отражения в Единой государственной информационной системе учета научно-исследовательских, опытно-конструкторских и технологических работ гражданского назначения» [2]. Данные темы попадают только после выделения финансирования из бюджета, т. е. после того, как государственное задание уже утверждено.

Отсутствие должного нормативно-правового и методического обеспечения порядка формирования государственного задания в науке приводит к возникновению следующих проблем:

1) каждое научное учреждение сепаратно определяет свои потребности в бюджетном финансировании в русле государственного задания, закладывает их в проект государственного задания и направляет учредителю, который с учетом финансовых возможностей следующего бюджетного периода либо утверждает их, либо сокращает. То есть уже на стадии формирования потребностей учреждения в финансовых средствах на научные исследования отсутствуют объективные показатели для расчета их размера, в связи с чем участник не может проверить обоснованность запрошенных исполнителем средств;

2) при распределении ассигнований, имеющихся у одного главного распорядителя бюджетных средств, между всеми подведомственными учреждениями отсутствуют какие-либо критерии для выделения одному учреждению большего размера ассигнований, а другому - меньшего;

3) отсутствует связь между механизмом формирования государственного задания и механизмом контроля за его выполнением: так как объективные показатели качества выполнения научно-исследовательских работ за счет средств государственного задания отсутствуют, то и сам участник, и Федеральная служба финансово-бюджетного надзора или Счетная палата Российской Федерации не имеют строгих ориентиров для проведения проверки 
эффективности использования бюджетных средств (фактически наличие документа о принятии учреждением работ по государственному заданию приравнивается к их надлежащему выполнению).

Решение указанных проблем возможно только при изменении концептуального подхода к формированию заказа в сфере науки - перехода от системы государственного заказа к системе «общественного» заказа.

Данная система должна основываться на следующих принципах для всех операторов инновирования: конкурентность; квалифицированность; сбалансированность между системой общественного заказа и инициативными исследованиями; допустимость обоснованного риска при осуществлении научной, научно-технической и инновационной деятельности; гласность формирования общественного заказа.

Все органы власти как операторы общественного заказа объявляют основные проблемы, подлежащие решению с помощью научно-исследовательских и опытно-конструкторских работ (далее - НИОКР), в рамках стратегического планирования. Способы решения указанных проблем путем проведения тех или иных НИОКР предлагают инициаторы общественного заказа - эксперты и научное сообщество.

Экспертное мнение о целесообразности выбора того или иного НИОКР, научного направления или проекта среди предложенных инициаторами общественного заказа может формировать Комиссия при Президенте Российской Федерации, обеспечение деятельности которой осуществляет Минобрнауки России. Состав Комиссии должен обеспечивать вхождение авторитетных экспертов по всем видам научных исследований (фундаментальные, прикладные, поисковые) и по инновационной деятельности.

При планировании бюджетных ассигнований на определенный календарный период федеральные органы исполнительной власти могут определять размер бюджетных ассигнований с учетом заключений комиссии.

Оператор общественного заказа может и формировать отдельные проекты, и собирать эти заказы в программы. Оценка эффективности деятельности оператора должна проводиться не по отдельным заказам, а по программе в целом (оцениваться должен кумулятивный эффект, а не эффект от каждого проекта).

Следует отметить, что изложенные соображения касаются практически только внутрироссийских инновационных проектов. Для инновационных проектов, когда инноватор или новатор - нероссийское лицо следует разработать специальные, оригинальные схемы регулирования.
В целом же пока предлагается следующая концептуальная канва трансформации российской новационно-инновационной сферы в части ее регуляционной регламентации со стороны органов государственного управления:

1) формируется комплексный организационноэкономический механизм инновирования на базе полноценного системотехнического проектирования внутренней и внешней сред инновирования;

2) этот механизм доопределяется в части внешнего нормативно-правового регулирования опятьтаки на базе построений системного анализа;

3) проводится тестирование новаций в государственном управлении экономикой и их доработка по результатам этого тестирования;

4) управленческие новации вводятся для повсеместного применения.

\section{Выводы}

Вышеизложенное дает основание сформировать следующие констатации, выводы и рекомендации:

1) сложившаяся ситуация в области инновационного развития российской экономики неприемлемо плоха и обнаруживает явно выраженные тенденции для усугубления, особенно в областях критических высоких технологий производства. Это порождает сильные социальные угрозы и угрозы национальной безопасности;

2) одной из основных кризисообразующих причин инновационного кризиса является низкое качество управления, в том числе - государственного регулирования;

3) среда инновирования структурируется как предметно ориентированная классическая маркетинговая среда, в которой новатор и инноватор образуют классическую диаду «поставщик-заказчик» в отношении новационной товарной продукции;

4) существующая нормативно-правовая база представлена несистемным конгломератом законов, указов и подзаконных актов различного уровня;

5) следует ввести институт общественного заказа и обеспечить мониторинг всех предложений по формированию общественного заказа на научные исследования. В рамках мониторинга должен проводиться анализ всех предложений о проведении НИОКР. Такой мониторинг может вести Минобрнауки России или иное функциональное министерство с одновременным установлением обязанности всех операторов общественного заказа размещать сведения в соответствующей государственной информационной системе. 


\section{Библиографический список}

1. Бюджетный кодекс Российской Федерации от 31.07.1998 г. № 145-Ф3 (БК РФ) (ред. от 28.07.2012) (с изменениями и дополнениями) [Электронный ресурс]. - Режим доступа: http://base.garant.ru/77664707/bdced85cc354ff 6a11911b30fbe61e5d (дата обрашения: 21.06.2018).

2. Постановление Правительства РФ от 12.04.2013 г. № 327 (ред. от 23.01.2018) «О единой государственной информационной системе учета научно-исследовательских, опытно-конструкторских и технологических работ гражданского назначения» (вместе с «Положением о единой государственной информационной системе учета научно-исследовательских, опытно-конструкторских и технологических работ гражданского назначения») [Электронный ресурс]. - Режим доступа: http://www. consultant.ru/document/cons_doc_LAW_145078 (дата обращения: 21.06.2018).

3. Постановление Правительства РФ от 11.10.2014 г. № 1042 «О внесении изменений и признании утратившими силу некоторых актов Правительства Российской Федерации» (с изменениями и дополнениями) [Электронный ресурс]. - Режим доступа: http://base.garant. $\mathrm{ru} / 70764846$ (дата обращения: 21.06.2018).

4. Базовый перечень государственных услуг (работ), оказываемых федеральными государственными организациями в сфере образования и науки, утв. Министерством образования и науки РФ 17.07.2014 г. № АП44/18вн. [Электронный ресурс]. - Режим доступа: https:// clck.ru/Db5eU (дата обращения: 21.06.2018).

5. Ведомственный перечень государственных услуг (работ), оказываемых (выполняемых) находящимися в ведении Минобрнауки России федеральными государственными учреждениями в качестве основных видов деятельности (утв. Министерством образования и науки РФ 18.07.2014 г. № АП-47/18вн) [Электронный ресурс]. - Режим доступа: https://xn--80abucjiibhv9a.xn -p1ai/\% D0\%B4 $\% \mathrm{D} 0 \% \mathrm{BE} \% \mathrm{D} 0 \% \mathrm{BA} \% \mathrm{D} 1 \% 83 \% \mathrm{D} 0 \% \mathrm{BC} \% \mathrm{D} 0 \% \mathrm{~B} 5 \% \mathrm{D} 0 \% \mathrm{BD}$ $\% \mathrm{D} 1 \% 82 \% \mathrm{D} 1 \% 8 \mathrm{~B} / 4312$ (дата обращения: 21.06.2018).

6. Ведомственный перечень государственных услуг (работ), оказываемых (выполняемых) находящимися в ведении Правительства РФ федеральными государственными учреждениями в качестве основных видов деятельности (утв. Министерством образования и науки РФ 07.04.2014 г. № АП-23/18вн) [Электронный ресурс]. Режим доступа: http://base.garant.ru/70636942 (дата обращения: 21.06.2018).

7. Положение о формировании государственного задания образовательным организациям высшего образования, подведомственным Минобрнауки России, в сфере научной деятельности (утв. Министерством образования и науки РФ 02.12.2013 г. № АП-125/14вн) [Электронный ресурс]. - Режим доступа: http://base. garant.ru/71199970 (дата обращения: 21.06.2018).

8. Бодрунов С. Д. Авиационно-промышленный комплекс России на рубеже XXI века: проблемы эффективного управления: [Монография] / С. Д. Бодрунов, О. Н. Дмитриев, Ю. А. Ковальков // Ч. 1 Ч. 2. - СПб: Корпорация «Аэрокосмическое оборудование», 2002 549 c. 475 c.

9. Гибадуллин А. А. Современные механизмы инновационного развития промышленности России [Текст]: [Монография] - М.: ГУУ, 2016. - 159 с.

\section{References}

1. Byudzhetnyj kodeks Rossijskoj Federacii ot 31.07.1998 № 145-FZ (BK RF) (red ot 28.07.2012) (s izmeneniyami i dopolneniyami). [The budget code of the Russian Federation dated July 31, 1998 № 145-FZ (BC RF) (as amended) (red of 28.07.2012). Part two. The budget system of the Russian Federation (articles 10-150). Section III. Expenses budgets (articles 65-87). Chapter 10. General provisions on budget expenditures (art.65-83)]. Available at: http://base.garant.ru/77664707/ bdced85cc354ff6a11911b30fbe61e5d (accessed 21.06.2018).

2. Postanovlenie Pravitel'stva RF ot 12.04.2013 № 327 (red. ot 23.01.2018) «O edinoj gosudarstvennoj informacionnoj sisteme ucheta nauchno-issledovatel'skih, opytno-konstruktorskih i tekhnologicheskih rabot grazhdanskogo naznacheniya» (vmeste $\mathrm{s}$ «Polozheniem o edinoj gosudarstvennoj informacionnoj sisteme ucheta nauchno-issledovatel'skih, opytno-konstruktorskih i tekhnologicheskih rabot grazhdanskogo naznacheniya»). [Resolution of the Government of the Russian Federation № 327 dated 12.04.2013 (ed. by 23.01.2018) «On the unified state information accounting system of scientific-research, experimental-design and technological works of civil appointment» (together with «Statute on the unified state information accounting system of scientific-research, experimental-design and technological works of civil appointment»)]. Available at: http://www.consultant.ru/ document/cons_doc_LAW_145078 (accessed 21.06.2018).

3. Postanovlenie Pravitel'stva RF ot 11.10.2014 № 1042 «O vnesenii izmenenij i priznanii utrativshimi silu nekotoryh aktov pravitel'stva Rossijskoj Federacii» (s izmeneniyami i dopolneniyami). [The order of the Government of the Russian Federation dated October 11, 2014 № 1042 «about modification and recognition become invalid for some acts of the Government of the Russian Federation» (with changes and additions)]. Available at: http://base.garant.ru/70764846 (accessed 21.06.2018).

4. Bazovyj perechen' gosudarstvennyh uslug (rabot), okazyvaemyh federal'nymi gosudarstvennymi organizaciyami v sfere obrazovaniya i nauki, utverzhdennyj Ministerstvom obrazovaniya i nauki RF 17.07.2014 № AP-44/18vn [The basic list of public services (works) provided by Federal state organizations in the field of education and science, approved by the Ministry of education and science of RussiaFederation dated July 17, 2014. № AP-44/18vn]. Available at: https://clck.ru/Db5eU (accessed 21.06.2018).

5. Vedomstvennyj perechen' gosudarstvennyh uslug (rabot), okazyvaemyh(vypolnyaemyh) nahodyashchimisya v vedenii Minobrnauki Rossii federal'nymi gosudarstvennymi uchrezhdeniyami v kachestve osnovnyh vidov deyatel'nosti, utverzhdennyj Ministerstvom obrazovaniya i nauki RF 18.07.2014 № AP-47/18vn [The departmental list of public services(works) provided (performed) by the Federal state institutions under the jurisdiction of the Ministry of education and science of Russia as the main activities, approved by the Ministry of education and science of RussiaFederation dated July 18, 2014. № AP-47/18vn]. Available at: https://xn-80abucjiibhv9a.xn--p1ai/\%D0\%B4\%D0\%BE\%D0\%BA\% $\mathrm{D} 1 \% 83 \% \mathrm{D} 0 \% \mathrm{~B}$ C $\%$ D $0 \%$ B $5 \%$ D $0 \%$ B D\%D1\%82\%D1\%8B/4312 (accessed 21.06.2018).

6. Vedomstvennyj perechen' gosudarstvennyh uslug (rabot), okazyvaemyh (vypolnyaemyh) nahodyashchimisya v vedenii Pravitel'stva Rossijskoj Federacii federal'nymi gosudarstvennymi uchrezhdeniyami v kachestve osnovnyh vidov deyatel'nosti. (utv. Ministerstvom obrazovaniya i nauki RF 07.04.2014 № AP-23/18vn). [The departmental list of the state services (works) rendered (performed) by the Federal pub- 
10. Гуреев П. М. Основы методологии исследования темпоральности инноваций: Монография. - М.: ГУУ, 2013. - $166 \mathrm{c}$.

11. Диваева Э. А. Современные методологические подходы к оценке инновационного развития экономики [Текст]: Монография - М.: ГУУ, 2013. - 105 с.

12. Золотова В. А. Управленческие проблемы и задачи формирования программы антикризисного управленческого инновирования в высокотехнологичное предприятие промышленности России - М.: КноРус, 2017 - 210 с.

13. Леонова Т. Н. Институты развития инновационной экономики: Монография. - М.: ГУУ, 2010. -97 с.

14. Толкачев П. С. Цели экономики и задачи инновационного развития России: Монография. - М.: ГУУ, 2011. $-231 \mathrm{c}$.

15. Dmitriev O. N. Conception of Managing of FuzzyInstitutional Meso-Level Organizational Separations in a Context of Product Projects Internationalization / O. N. Dmitriev, S. V. Novikov// European Research Studies Journal, Volume XX, Issue 4B, 2017. Режим доступа: https:// w w w . e r s j.e u / i n d e x. p h p ? o p t i o n $=\mathrm{co} \mathrm{m}$ content\&task=view\&id=1011 (дата обращения: 21.06.2018). lic institutions which are under authority of the Government of the Russian Federation as primary activities. (app. Ministry of education and science of the Russian Federation dated 7 April 2014 n AP-23 / 18vn)]. Available at: http://base.garant.ru/70636942 (accessed 21.06.2018).

7. Polozhenie o formirovanii gosudarstvennogo zadaniya obrazovatel'nym organizaciyam vysshego obrazovaniya, podvedomstvennym Minobrnauki Rossii, v sfere nauchnoj deyatel'nosti (utv. Ministerstvom obrazovaniya i nauki RF 02.12.2013 № AP-125/14vn). [Regulations on formation of the state task to the educational organizations of the higher education subordinated to the Ministry of education and science of Russia, in the field of scientific activity (UTV. Ministry of education and science of the Russian Federation dated 2 December 2013 n AP-125 / 14vn)]. Available at: http://base.garant. $\mathrm{ru} / 71199970$ (accessed 21.06.2018).

8. Bodrunov S. D. Dmitriev O. N., Kovalkov Yu. A. Aviacionno-promyshlennyj kompleks Rossii na rubezhe XXI veka: problemy ehffektivnogo upravleniya [Aviation-industrial complex of Russia at the turn of the XXI century: problems of efficient management ] // Part 1/ Part 2. SPb: Korporaciya «Aehrokosmicheskoe oborudovanie», [Corp. «Aerospace equipment»], 2002. 549 p.

9. Gibadullin A. A. Sovremennye mekhanizmy innovacionnogo razvitiya promyshlennosti Rossii: [Modern mechanisms of innovative development of Russian industry]. M.: GUU, 2016. 159 p.

10. Gureev, M. P. Osnovy metodologii issledovaniya temporal'nosti innovacij [Fundamentals of research methodology temporality of innovations: Monograph]. M.: GUU, 2013. 166 p.

11. Divaeva E. A. Sovremennye metodologicheskie podhody $\mathrm{k}$ ocenke innovacionnogo razvitiya ehkonomiki. [Modern methodological approaches to the assessment of innovative development of the economy]: Monograph. M.: GUU, 2013. 105 p.

12. Zolotova V. A. Upravlencheskie problemy i zadachi formirovaniya programmy antikrizisnogo upravlencheskogo innovirovaniya $\mathrm{v}$ vysokotekhnologichnoe predpriyatie promyshlennosti Rossii. [Management problems and problems of formation of the program of anti-crisis management innovation in the high - tech enterprise industry of Russia]-M.: KnoRus, 2017. 210 p.

13. Leonova T. N. Instituty razvitiya innovacionnoj ehkonomiki. [Institutions of innovation economy development]: Monograph. M.: GUU, 2010. 97 p.

14. Tolkachev P. S. Celi ehkonomiki i zadachi innovacionnogo razvitiya Rossii. [Economic Goals and objectives of innovative development of Russia]: Monograph. M.: 2011. 231 p.

15. Dmitriev O. N., Novikov S. V. Conception of Managing of Fuzzy-Institutional Meso-Level Organizational Separations in a Context of Product Projects Internationalization European Research Studies Journal, Volume XX, Issue 4B, 2017. Available at: https://www.ersj.eu/index.php?option=com_content\&task=view\&id=1011 (accessed 21.06.2018). 